\title{
Precision intrauterine contraception may significantly increase continuation of use: a review of long-term clinical experience with frameless copper-releasing intrauterine contraception devices
}

This article was published in the following Dove Press journal:

International Journal of Women's Health

29 April 2013

Number of times this article has been viewed

\author{
Dirk Wildemeersch' \\ Ansgar Pett ${ }^{2}$ \\ Sohela Jandi² \\ Thomas Hasskamp ${ }^{3}$ \\ Patrick Rowe ${ }^{4}$ \\ Marc Vrijens ${ }^{5}$ \\ 'Gynecological Outpatient Clinic and \\ IUD Training Center, Ghent, Belgium; \\ ${ }^{2}$ Gynecological Outpatient Clinic, \\ Berlin, Germany; ${ }^{3}$ Gynecological \\ Outpatient Clinic, Münster, Germany; \\ ${ }^{4}$ Formely IUD Research Group at \\ the UNDP/UNFPA/WHO/World \\ Bank Special Programme of Research, \\ Development and Research Training \\ in Human Reproduction, World Health \\ Organization, Geneva, Switzerland; \\ ${ }^{5}$ Gynecological Outpatient Clinic, \\ Ghent, Belgium
}

Correspondence: Dirk Wildemeersch Gynecological Outpatient Clinic and IUD Training Center, 44 Franklin Rooseveltlaan, Ghent 9000 , Belgium Tel +32 50600900

Fax +32 92342926

Email d.wildemeersch@skynet.be
Objective: The purpose of this paper is to review the experience with the frameless, anchored, GyneFix copper-releasing intrauterine contraceptive devices (IUCDs/IUDs) (Contrel Europe, Belgium), and to demonstrate their high acceptability and low rate of discontinuation of use, which could contribute to current efforts that aim to reduce radically the high number of unintended pregnancies and induced abortions, particularly in young women.

Materials and methods: This paper is based on studies that examined the differences in uterine volume and cavity size, related to age and parity, and on original clinical research data and practical experience with frameless copper IUDs, as well as on literature data on the IUDendometrial cavity relationship of conventional IUDs, with special reference to side effects and user discontinuation.

Results: The mean transverse diameter in nulliparous and parous women is significantly less than the length of the transverse arm of the TCu380A IUD (ParaGard, Duramed, NY, USA) or the levonorgestrel intrauterine system (Mirena, Bayer, Germany). Small, frameless, flexible, and unidimensional copper IUDs appear to be well tolerated, with less impact on menstrual bleeding, resulting in low discontinuation rates when compared with standard-size conventional IUDs, which often result in increased expulsion rates, complaints of pain and erratic or increased menstrual bleeding, and subsequent high rates of discontinuation, particularly in young women.

Conclusion: The unidimensional GyneFix IUDs fit the majority of uterine cavities. An IUD that fits is likely to result in increased tolerance and continued use of the method. As this would appeal to women, the logical result should be greater use of the method and fewer unintended pregnancies and induced abortions. Recommending the standard TCu380A (ParaGard) IUD or the Mirena levonorgestrel intrauterine system, primarily developed for use in parous women, for general use in nulliparous and adolescent women should be done with caution in the light of current scientific evidence, except if 3-D sonography indicates that the uterine cavity is sufficiently large.

Keywords: GyneFix; anchored IUS; frameless IUS; tolerance, acceptability, continuation, discontinuation

\section{Introduction}

Increasing use of long-acting reversible contraception (LARC) as a strategy to prevent unintended pregnancy was the subject of a recent publication. ${ }^{1}$ The article reviews the LARC methods and expresses the need to increase the use of these methods in 
an attempt to reduce the global "epidemic" of unintended pregnancies, particularly in young women. The US has the highest teen pregnancy rate in the industrialized world. The Centers for Disease Control and Prevention states that one-third of girls are pregnant before the age of 20 years. Teenpregnancy.org, a site managed by the National Campaign to Prevent Teen and Unplanned Pregnancy, states: "There are 750,000 teen pregnancies annually. Eight in ten of these pregnancies are unintended and 81 percent are to unmarried teens." ${ }^{2}$ The intrauterine contraceptive device (IUCD/IUD) occupies a prominent role in reducing unintended pregnancy rates. They have a higher continuation of use than implants and depot medroxyprogesterone acetate. ${ }^{3}$ The IUD is also an excellent candidate for use immediately following induced first-trimester abortion, resulting in significantly fewer repeat abortions. ${ }^{4}$ In addition, copper IUDs are more effective than emergency contraceptive pills, providing long-term protection simultaneously, ${ }^{5}$ and they are more cost-effective than any other method. ${ }^{6}$

As IUDs are strategically important for preventing unintended pregnancy, they can only contribute to reducing unintended pregnancy if women or couples continue to use the method. The Mirena (Bayer, Germany) and ParaGard (Duramed, NY, USA) IUDs are the only two IUDs currently available in the US. As uterine cavities differ considerably in size and shape, and the uterus is subject to changes in size and volume during the menstrual cycle (see below), one standardsize IUD will not fit in uterine cavities that differ in size and volume from woman to woman and from time to time in the same woman (eg, following birth, the presence of fibroids). Clinical experience shows that geometric incompatibility between the rigid or semirigid IUD and the uterine cavity can lead to partial or total expulsion, embedment and perforation of the uterine wall, pain, unintended pregnancy, and abnormal or heavy uterine bleeding, resulting in removal of the device. ${ }^{7}$ Studies of the uterine cavity, conducted several decades ago, suggested that individual variation in uterine cavity sizes are comparable with the individual variations in size and shape of feet. ${ }^{7-10}$ This paper examines the performance of frameless devices in parous and nulliparous women. An IUD that fits like a shoe may be helpful to significantly contribute to current efforts to reduce the number of unintended pregnancies, particularly in young nulliparous and adolescent women.

\section{Materials and methods}

Two main areas are examined in this paper: the first is the size of the uterine body as well as its cavity according to age and parity, and the second is the clinical evaluation of the frameless IUDs particularly related to the discontinuation rates for medical reasons.

Of the few publications that could be found in the literature on the direct measurement of the size of the uterine cavity according to age and parity and volume of the uterus according to age and parity, only those publications that seemed relevant were selected (see below).

\section{Results \\ Uterine volume}

Da Costa et al conducted a study in 828 women and girls between 10 and 40 years old using transabdominal ultrasonography. ${ }^{11}$ Women were divided into two groups: group 1 consisted of 477 (57.6\%) adolescents, and group 2 comprised $351(42.3 \%)$ women $20-40$ years old. Uterine volume increased with the presence of menarche, age, and parity $(P<0.05)$. Nulliparous and primiparous adolescents younger than 18 years old had a smaller uterine volume $-41.3 \pm 17.9$ and $51.6 \pm 19.7 \mathrm{~cm}^{3}$, respectively, than nulliparous and primiparous women $20-40$ years old $(P<0.001)$. The red square in Figure 1 focuses on the 15- to 20-year-old adolescents.

\section{Uterine cavity: importance of the cavity width}

In-depth studies have been conducted, using measuring devices inserted in the uterus, by Hasson ${ }^{7}$ and $\mathrm{Kurz}^{8}$ (see below) Benacerraf ${ }^{16,49}$ using 3-D sonography. Kurz measured the uterine width in parous and nulliparous women. Figure 2 shows the instrument used by Kurz for measuring the fundal transverse diameter in vivo.

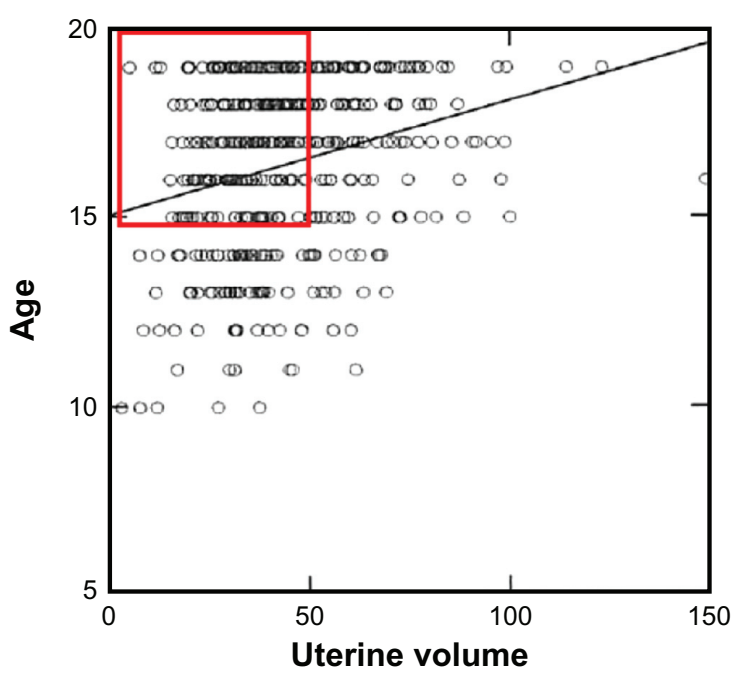

Figure I The mean value in nulliparous and primiparous girls between 15 and 20 years old is $\sim 40-50 \mathrm{~cm}^{3}$.

Note: The red rectangle shows that many adolescents have a small uterus. Reprinted from Ultrasound in Medicine \& Biology, Volume 30, Gadelha Da Costa et al, Uterine volume in adolescents, pages 7-10, Copyright () 2004." 


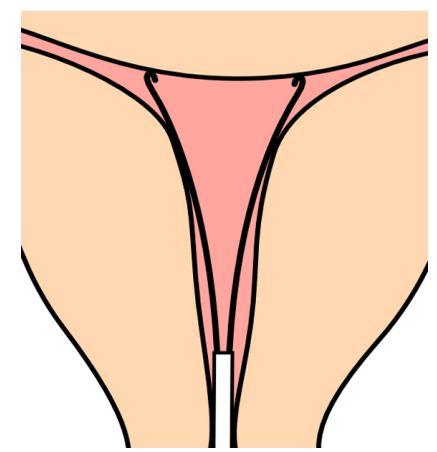

Figure 2 Illustration of how the fundal transverse diameter was measured with a specially designed instrument (cavimeter).

The mean width of the uterine cavity at the fundal level (fundal transverse diameter) in 795 nulliparous and parous women between 15 and 40 years of age was $\sim 24-26 \mathrm{~mm}$ (Table 1). ${ }^{8}$ In order to optimize the spatial compatibility between the standard T-shaped IUD and the uterine cavity, Kurz adapted T-shaped IUDs, following measurement of the transverse diameter, prior to inserting the IUD. The transverse arm of a T-shaped IUD was shortened from its standard length of $32 \mathrm{~mm}$ to the individually measured transverse diameter or slightly less (Figure 3 ). He found that the fundal transverse dimension is of paramount importance with respect to IUD acceptance, as women tolerated the IUD much better.

Similar studies were conducted by Hasson in the early 1980s with the use of his Wing Sound. ${ }^{7}$ According to Hasson, "The optimum geometric relationship of a properly inserted IUD is one in which the greatest transverse dimension of the IUD is equal or slightly in excess of the fundal transverse dimension" (Figure 4). These geometric relationships promote IUD retention and stability while minimizing endometrial/myometrial trauma. On the other hand, Hasson noted that "IUDs of which the transverse arm is significantly greater or smaller than the fundal transverse diameter have unfavorable geometric relationships with the uterine cavity."

Furthermore, Hasson found that the uterine shape and dimensions during the different phases of the menstrual cycle modulate the relationship between the IUD and the host

Table I Fundal transverse diameter $(\mathrm{mm})$ according to age and parity (Kurz Cavimetric measurements ${ }^{8}$ )

\begin{tabular}{llllll}
\hline Age & $\mathbf{1 5 - 1 9}$ & $\mathbf{2 0 - 2 4}$ & $\mathbf{2 5 - 2 9}$ & $\mathbf{3 0 - 3 4}$ & $\mathbf{3 5 - 3 9}$ \\
\hline Mean \pm SD & $24.8 \pm 2.5$ & $23.9 \pm 3.0$ & $24.8 \pm 3.2$ & $24.7 \pm 3.3$ & $24.9 \pm 1.1$ \\
No of women & 28 & 221 & 232 & 175 & 96 \\
\hline Parity & $\mathbf{0 . 0}$ & $\mathbf{0 . 1}(+)^{*}$ & $\mathbf{I}$ & $\mathbf{2}$ & $\mathbf{3}(+)$ \\
\hline Mean \pm SD & $23.1 \pm 3.1$ & $23.8 \pm 3.3$ & $24.5 \pm 3.0$ & $25.7 \pm 3.5$ & $26.0 \pm 2.3$ \\
No of women & 493 & 124 & 103 & 62 & 13 \\
\hline
\end{tabular}

Note: ${ }^{*} 0 . \mathrm{I}(+)=$ no parity, one abortion or more.

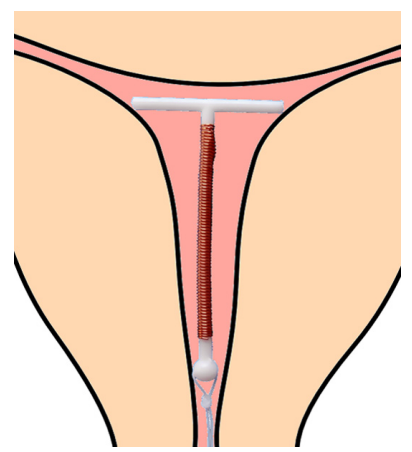

Figure 3 Adapted T-shape intrauterine device with transverse arm of $18 \mathrm{~mm}$

endometrial cavity. Other authors found that uterine contraction frequency shows an increase during the follicular phase, followed by a period of uterine quiescence during the luteal phase. ${ }^{12}$ If these contractions are severe, they can compress, distort, displace, and expel the IUD, particularly if the IUD is too big and is not capable of adaptive changes. ${ }^{9}$

The length of the IUD does not seem to be important clinically, unless there is a great difference between cavity length and the length of the stem of the IUD. The performance between standard-length IUDs and short IUDs in nulliparous women appears similar. ${ }^{13}$ Canteiro et al concluded that the development of an IUD with a shorter length of the stem appears unnecessary, since current models fit most women, including nulligravid women. ${ }^{14}$

Although these "cavimetric" studies may have had some limitations, the conclusions were confirmed in recent 3-D ultrasound studies. ${ }^{15}$ Also, Benacerraf et al studied the width of the normal uterine cavity and assessed the relationship of this width with parity, gravidity, age, and uterine volume. ${ }^{16}$ Figure 5 shows a 3-D view of the uterine cavity. Table 2 shows the mean fundal transverse diameter in nulliparous women, with mean age of 29 years, and in parous women.
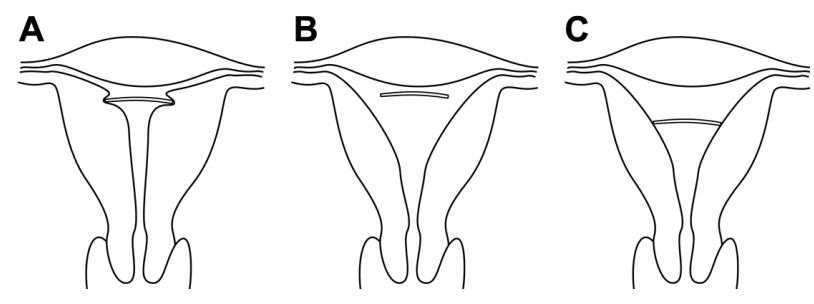

Figure 4 (A-C) Geometric relation of a properly inserted intrauterine device (IUD) to endometrial cavities with various inappropriate fundal transverse dimension. (A) Fundal transverse dimension significantly smaller than the length of the transverse arm of the IUD; (B) fundal transverse dimension significantly greater (initial position of the IUD); (C) fundal transverse dimension significantly greater (possible subsequent position of the IUD). 


\section{Experience with the copper-releasing frameless GyneFix IUDs}

Only studies with the original frameless Cu-Fix or GyneFix IUD are described in this section. Table 3 provides the main events and cumulative discontinuation rates in both randomized and non-randomized comparative clinical trials. Further information about these studies is given below.

The first frameless IUD had an effective copper surface area of $390 \mathrm{~mm}^{2}$. The International Study Group on Intrauterine Drug Delivery of Ghent University, Belgium, initiated a pilot study some 25 years ago with this device, named $\mathrm{Cu}$-Fix as the copper is anchored to the uterine fundus. The $\mathrm{Cu}$-Fix 390 was inserted by six investigators in 382 women, and 4851 woman-months of experience were accumulated after 18 months. Close to $40 \%$ of the devices were inserted in nulligravid/nulliparous women. ${ }^{17}$

Later, an international multicenter study was set up by the study group in eleven centers, involving 20 investigators. Minor improvements were made both to the device and the inserter prior to the study. The effective surface area of the IUD used in this study was $330 \mathrm{~mm}^{2}$. Insertions were performed in 1039 women, of whom $27 \%$ were nulligravid. The subjects were followed for 36 months, generating close to 20,000 woman-months of experience. ${ }^{18}$

In another 3-year randomized comparative study, the GyneFix 330 IUD was compared with the TCu380A IUD (ParaGard) in six centers in China. Approximately 300 women in each treatment arm were enrolled, and only parous women were included in the study. ${ }^{19}$ It is noteworthy that investigators in this study had also participated in a World Health Organization study using the frameless Flexigard

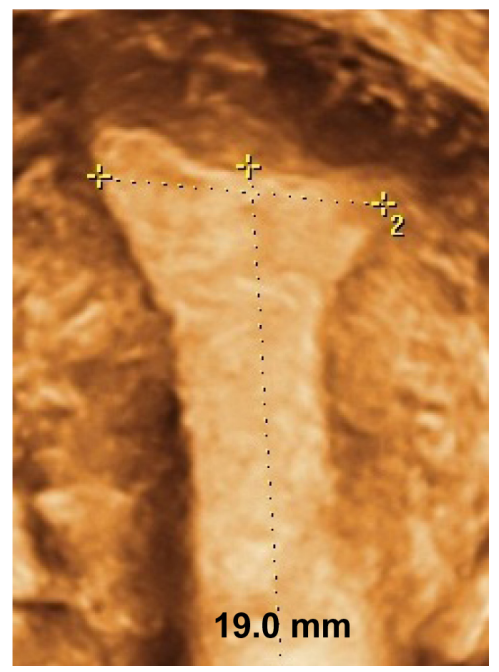

Figure 5 3-D coronal view of the uterine cavity, demonstrating the measurement of the fundal transverse dimension $(19.0 \mathrm{~mm})$.
Table 2 Fundal transverse diameter $(\mathrm{mm})$ according to gravidity/ parity (3-D measurements)

\begin{tabular}{|c|c|c|c|}
\hline $\begin{array}{l}\text { Gravidityl } \\
\text { Parity (n [\%]) }\end{array}$ & $0(n=91)$ & $I(n=38)$ & $>I(n=8 I)$ \\
\hline 0 & $91(100.00)$ & $18(47.3)$ & $3(3.7)$ \\
\hline I & & $20(52.6)$ & $9(I I . I)$ \\
\hline$>1$ & & & $69(85.1)$ \\
\hline $\begin{array}{l}\text { Mean transverse } \\
\text { diameter (range) }\end{array}$ & $27.1(20.2-34.1)$ & $29.6(22.9-36.3)$ & $31.1(24.6-37.5)$ \\
\hline $\begin{array}{l}\text { Mean volume } \\
\left(\mathrm{cm}^{3}\right)(\mathrm{SD})^{*}\end{array}$ & $55.3(25.7)$ & $66.4(29.2)$ & I03.I (33.1) \\
\hline
\end{tabular}

Note: *The width of the uterine cavity corresponds strongly with the overall uterine volume. Reprinted from Obstetrics and Gynecology, Volume II6, Benacerraf et al, Width of the normal uterine cavity in premenopausal women and effect of parity, pages305-310. Copyright (C) 2010.16

Promotional and commercial use of the material in print, digital or mobile device format is prohibited without the permission from the publisher Lippincott Williams \& Wilkins. Abbreviation: SD, standard deviation.

IUD. In this study, the prototype Flexigard inserter was used. Due to the shortcomings of the applicator as well as the IUD itself, many providers experienced failed insertions, which were much less frequent with the improved GyneFix inserter. Studies conducted by the World Health Organization with the frameless Flexigard copper IUD (a frameless variant of GyneFix) will not be discussed in this section, as these studies were not conducted with the device and inserter that was originally developed by the inventor and which was approved for marketing in the European Union (see Wildemeersch et $\mathrm{al}^{20}$ ).

Two additional studies were conducted to evaluate the efficacy of a "mini" version of the frameless intrauterine system with copper surface area of $200 \mathrm{~mm}^{2}$. The small GyneFix version consists of four copper cylinders instead of six, and is only $2 \mathrm{~cm}$ long. A total of 392 insertions were performed in an open nonrandomized study in parous (76\%) and nulligravid/nulliparous (24\%) women in Belgium and China. Women were followed up for a minimum of 3 years, up to 5 years. ${ }^{21}$ In addition, a menstrual blood-loss study was conducted in 60 parous and nulliparous GyneFix 200 users using a pictorial visual assessment chart. ${ }^{22}$ The results of this study are briefly discussed in the Discussion section.

The GyneFix 330 IUD was also tested for immediate postabortal application up to 10 weeks gestation. Initially, 112 insertions were performed in an international multicenter trial, with follow-up from 1 to 38 months. ${ }^{23}$ The trial was later extended to other centers. ${ }^{24}$ The findings (eg, absence of expulsion) are not discussed here, but the cardinal event rates and acceptability of the IUD were similar to those obtained in the earlier studies (data on file). 
Table 3 Number of women, gravidity/parity, and gross cumulative discontinuation rates per 100 users of GyneFix 330 and GyneFix 200 IUDs.

\begin{tabular}{|c|c|c|c|c|c|}
\hline $\begin{array}{l}\text { Study } \\
\text { Copper surface area }\left(\mathrm{mm}^{2}\right) \\
\text { Follow-up } \\
\text { Interval/postabortal }\end{array}$ & $\begin{array}{l}\text { No of } \\
\text { women }\end{array}$ & $\begin{array}{l}\text { \% nulligravid/ } \\
\text { nulliparous }\end{array}$ & Pregnancy & Expulsion & $\begin{array}{l}\text { Removal rate } \\
\text { for bleeding/ } \\
\text { pain }\end{array}$ \\
\hline $\begin{array}{l}\text { Wildemeersch et al }{ }^{17} \\
\text { GF390 - } 18 \text { months } \\
\text { Interval }\end{array}$ & 382 & 38.5 & 0.3 & 0.6 & 3.1 \\
\hline $\begin{array}{l}\text { Van Kets et al } \\
\text { GF330 - } 36 \text { months } \\
\text { Interval }\end{array}$ & 1039 & 26.7 & 0.5 & 0.7 & 3.8 \\
\hline $\begin{array}{l}\text { Wu et al }{ }^{19, *} \\
\text { GF330 - } 36 \text { months } \\
\text { Interval }\end{array}$ & 302 & 0.0 & 0.0 & $3.0 *$ & 4.5 \\
\hline $\begin{array}{l}\text { Cao et } \mathrm{al}^{21} \\
\text { GF200 - } 60 \text { months } \\
\text { Interval }\end{array}$ & 392 & 24 & 0.5 & 0.4 & 0.8 \\
\hline $\begin{array}{l}\text { Batár et al }{ }^{23} \\
\text { GF330 - } 12 \text { months }\end{array}$ & 112 & - & 0.0 & 0.0 & 5.0 \\
\hline Postabortal up to 10 weeks & & & & & \\
\hline $\begin{array}{l}\text { Gbolade }^{24} \\
\text { GF330 - I follow-up in } 30 \text { women } \\
\text { Postabortal up to I } 3 \text { weeks }\end{array}$ & 44 & - & 0.0 & 0.0 & $\begin{array}{l}3 \text { removals for } \\
\text { bleeding }\end{array}$ \\
\hline $\begin{array}{l}\text { Martinez et a }{ }^{25, *} \\
\text { GF330 - } 12 \text { months } \\
\text { Interval }\end{array}$ & 1684 & 18.6 & 0.3 & $5.6 *$ & 3.0 \\
\hline
\end{tabular}

Note: *Majority of investigators were not trained.

Abbreviation: IUD, intrauterine device.

A working group of Spanish professionals (GESEG), formed specifically with the aim of studying the frameless IUD, conducted a prospective, multicenter, observational study of GyneFix in 1684 women. ${ }^{25}$ The study focused on difficulties encountered during the insertion procedure and symptoms experienced during insertion. Women were followed up for 12-24 months. A total of $18.6 \%$ of the women were nulliparous. The results of this study are discussed further below.

\section{Discussion}

The clinical trials covered in this paper represent 3563 insertions in total, of which 832 were conducted at interval (between menstruations) in nulligravid and nulliparous women. The initial clinical trials were conducted with the GyneFix 330 IUD. More recently, the GyneFix 200 was preferred for use in all nulliparous women. A description of the GyneFix 200 used in clinical trials is provided in Figure 6. Since its inception, minor improvements to the anchoring knot have been made. All GyneFix 390 and 330 studies were conducted with an anchoring knot which was tied using a 00 -gauge suture. The GyneFix 200 was provided with a 0 -gauge suture. With this suture, the anchoring knot is slightly thicker, but the main advantage is that the anchoring knots are consistent in all manufactured devices, resulting in significantly better retention. ${ }^{26}$ Further, it was thought that by making the anchor visible on sonography, the safety of the technique would be improved and more IUD providers would be inclined to learn the anchoring technique. An ultrasound check could especially be indicated if the provider has some doubt about the insertion. Figure 7 shows how the "visualization" was realized. All frameless devices are currently provided with the improved anchoring knot and with the visualization element.

LARC methods (IUDs and implants) are many times more effective in preventing unintended pregnancy than methods that depend on user adherence. ${ }^{27,28}$ Even if the contraceptive pill, patch, or vaginal contraceptive ring is provided free of charge, discontinuations at 1 year are in the order of approximately $50 \% .{ }^{29}$ In the US, the proportion of "contraceptors" (primarily IUDs) using LARC increased significantly from $2.4 \%$ in 2002 to $3.7 \%$ in 2007 and $8.5 \%$ in $2009 .{ }^{30} \mathrm{In}$ Europe, approximately $10 \%$ use LARC. ${ }^{31}$ According to the contraceptive CHOICE project, women express a significant interest in LARC. In the CHOICE cohort, most subjects aged 18 years and older selected intrauterine contraception $(\sim 70 \%)$ while most of the 14- to 17-year-old subjects preferred the implant (63\%). $)^{32,33}$ 


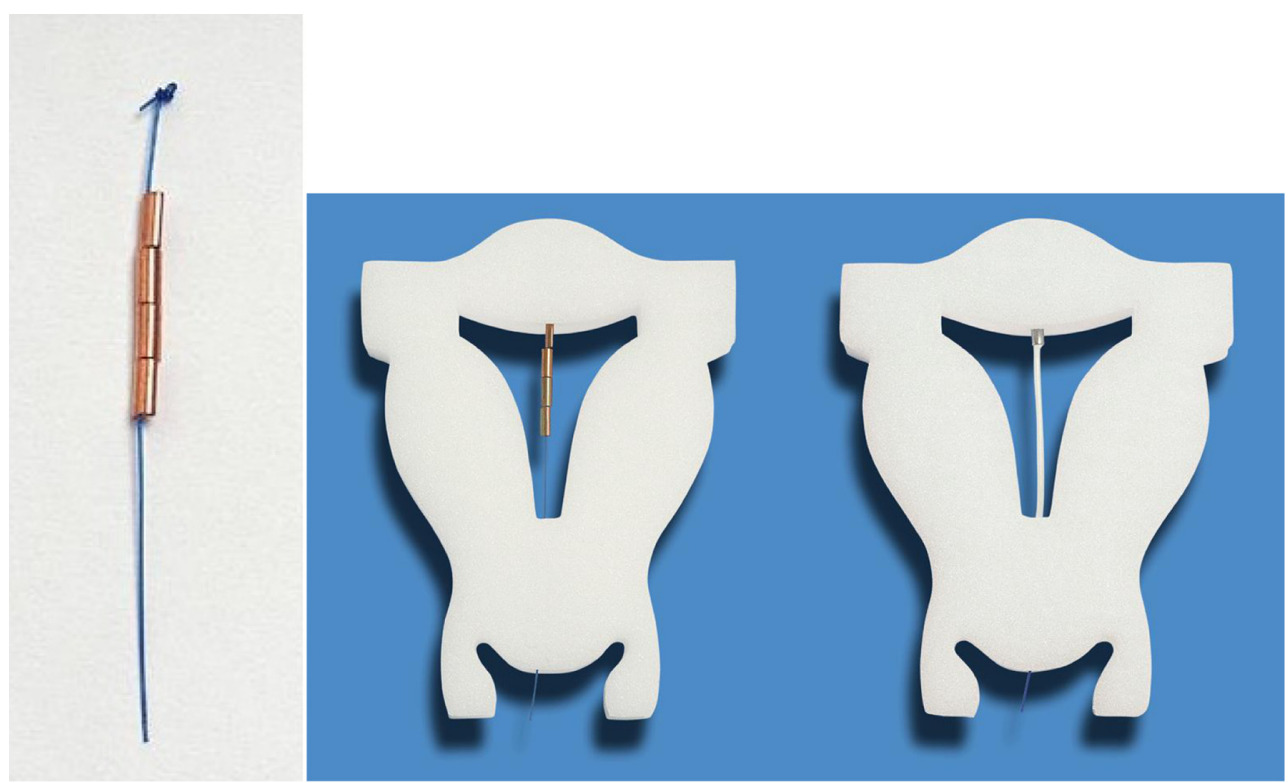

Figure 6 GyneFix 200 (Contrel Europe, Belgium), real size (left), in situ in foam uterus (middle), compared with the frameless FibroPlant-LNG (Contrel Europe, Belgium), which is derived from the frameless copper-releasing intrauterine device (IUD) (right).

Notes: The GyneFix 200 IUD, as used in the clinical trials, consists of four copper sleeves (instead of six with the longer GyneFix 330 IUD), each 5 mm in length and approximately $2.2 \mathrm{~mm}$ in diameter. The four copper sleeves are threaded on the polypropylene suture thread, and the uppermost and lowest sleeves are crimped onto it. A single knot is made in the upper portion of the thread, which serves as a small retention body when inserted in the myometrium of the uterine fundus at a controlled depth of $1.0 \mathrm{~cm}$. The minimum effective life of the GyneFix 200 IUD is 5 years. The FibroPlant LNG-IUS is not discussed in this paper.

A study conducted in the UK showed that a high proportion of practitioners $(80.2 \%)$ endorse the role of LARC in preventing teenage pregnancy, but fewer than half $(47.1 \%)$ see them as becoming popular. Lack of skill in providing the method was seen by $60.6 \%$ as a barrier to provision of longacting methods of contraception. Half of respondents (50.3\%) thought that irregular bleeding would deter women from using implants and injectable contraceptives, and $20.6 \%$ were concerned about high discontinuation rates. Misconceptions about side effects of contraceptive methods were common. ${ }^{34}$

LARC methods offer huge advantages to prevent unintended pregnancy, since women only need a yearly check following the first follow-up after fitting. Imperfect

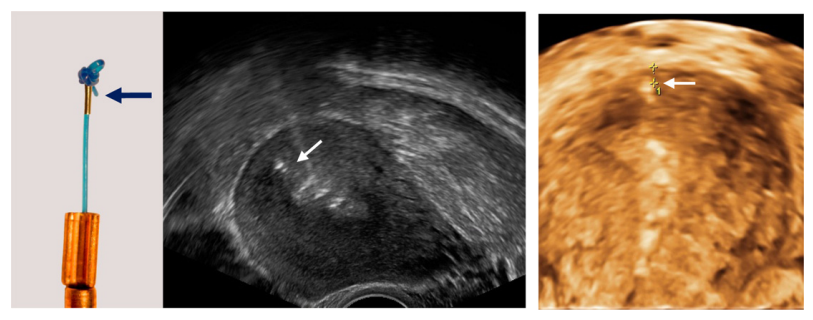

Figure 7 The current intrauterine device (IUD) is provided with a "visualized" anchor.

Notes: The anchor with visualization element (magnification $\times 1.5$ ) consists of the anchoring knot and a tiny medical grade stainless steel element (AISI 3I6L/I.4404) (2 mm long and $0.5 \mathrm{~mm}$ in diameter) (left). 2-D and 3-D ultrasound showing the properly located anchor (arrow) as well as the frameless IUD in the uterine cavity of a young woman (middle 2-D and right 3-D). contraceptive adherence leads to substantial unintended pregnancies and high, avoidable costs. Among reproductive health professionals, some conclude that the contraceptive model should be changed by making LARC the default option, ${ }^{35}$ as improved uptake of LARC may significantly diminish the number of unintended pregnancies and induced abortions and generate health-care cost savings by reducing contraceptive nonadherence. ${ }^{36} \mathrm{~A}$ recent American Congress of Obstetricians and Gynecologists opinion paper encourages the use of LARC methods (IUDs and implants). ${ }^{37}$

In a recent review of these methods, Blumenthal et al conclude that LARC methods are safe and effective and are appropriate for a wide range of women. ${ }^{1}$ However, based on a safety analysis of the eleven international clinical trials with the subdermal contraceptive implant, Implanon (Merck \& Co, NJ, USA), including findings from 942 women followed for 1-5 years, the review reveals that the overall continuation rate was only $32.7 \%$, the most commonly reported reasons for discontinuation being bleeding irregularities and other hormone-related side effects (eg, headache, weight increase, acne, breast pain, and emotional liability). ${ }^{38}$

The TCu380A IUD (ParaGard) and the levonorgestrel intrauterine system (LNG-IUS; Mirena), the only IUDs available in the US, have the advantage that they have a higher continuation of use than implants. ${ }^{3}$ Copper IUDs are nonhormonal, and the systemic side effects of the LNG-IUS 
are minor. They are, therefore, proposed as an appropriate method for use by young women and adolescents in the US and elsewhere. ${ }^{39-41}$ In-depth analysis, however, shows that cumulative copper IUD discontinuation rates for various reasons (mostly bleeding and pain) are one in four to one in two over 5 years of use, with significantly higher rates in adolescent and young nulliparous women. Hubacher's review of copper IUDs revealed that nulliparous women experience higher rates of expulsion and removals for bleeding and/ or pain compared with parous women. ${ }^{42}$ Higher pain and expulsion rates were also found in studies with the LNG-IUS (Mirena) conducted in nulliparous and adolescent women. ${ }^{43-46}$ Similarly, heavy menses and dysmenorrhea are the most frequent reasons for removal of the TCu380A (ParaGard) in the first year after insertion. ${ }^{47}$ The rates for removal are no better for adolescent mothers, as shown in a recent study with ParaGard and Mirena conducted by Teal and Sheeder. ${ }^{48}$ The 12-month continuation rate was only $55 \%$; most reasons for removal were expulsion (14.2\%), pain (12.2\%), and bleeding $(7.4 \%)$. The pregnancy rate was $4.7 \%$. According to the authors, there was no difference between the IUD types.

Benacerraf, Shipp, and others, including the Ghent Study Group, conducted sonographic studies in symptomatic women using various copper and LNG-releasing IUDs. ${ }^{49-51}$ They compared women with abnormally and normally located IUDs, with respect to their indication for sonography, and found that the proportion of patients whose principal indication for sonography was bleeding, pain, or bleeding and pain was significantly greater in those with an abnormally located IUD, including embedded IUDs, compared with those whose IUD was not located abnormally on 3-D ultrasonography. It was noted that standard 2-D ultrasound is not able to detect many abnormally located IUDs, particularly with regard to abnormal location of the side arms of the IUD. This was confirmed in 2-D and 3-D ultrasonography studies conducted by the authors of the present paper (unpublished).

The mean transverse dimensions in nulliparous and primiparous women given in Table 2 are slightly higher than those measured by $\mathrm{Kurz}^{8}$ using his cavimeter. This could be attributed to the significantly older mean age of women (29 years) and the smaller number of participants: 129 vs 720 , respectively. In the study conducted by Kurz, approximately $75 \%$ of women were young nulligravid/nulliparous between 15 and 24 years of age. These transverse dimensions are far less than the length of the transverse arm of the ParaGard IUD and Mirena LNG-IUS, which is $32 \mathrm{~mm}$, with both devices resulting in distortion, displacement, and expulsion of the IUD, as demonstrated in this review.
Benacerraf et $\mathrm{al}^{49}$ produced an informative slide set, available online (http://ebookbrowse.com/benacerraf-3din-gynecology-pdf-d263544493), showing various illustrations of abnormally located IUDs, comparing 2-D with 3-D sonography. Figure 8 shows some examples of embedded IUDs and Figures 9 and 10 the limited value of 2-D ultrasonography in determining the position of the transverse arm of the IUD. To treat women with side effects, one of the coauthors removes the IUD/IUS and trims the transverse arm. An example of a "trimmed" Mirena IUS is shown in Figure 11.

The results of the studies reported in the present paper suggest that the frameless GyneFix IUD is effective and well tolerated, resulting in low rates of discontinuation for medical reasons. The strength of the technology is that after a period of 25 years, the same conclusions can be made as those made following the initial trials during the early 1990s: “. . . being well tolerated, the device is retained well by the uterus and is both effective and safe. The design is extremely simple and insertion and retrieval is easy." 18 The frameless copper IUD has only one dimension, which explains its adaptation in cavities of every size and shape. These characteristics of precision intrauterine contraception are thought to be responsible for the low rate of side effects and consequently high user continuation. These features do not allow the uterus to exert expulsive forces on the IUD, in contrast with conventional IUDs.

As the smaller $200 \mathrm{~mm}^{2}$ version has similar efficacy to the $330 \mathrm{~mm}^{2}$ earlier version, and does not significantly increase menstrual blood loss, it was thought that it would be more suitable for adolescent and young nulliparous women. The high effective surface area, significantly higher than that of conventional copper IUD with nominal surface area of $200 \mathrm{~mm}^{2}$, allows a reduction in the overall surface area of the IUD. ${ }^{52}$

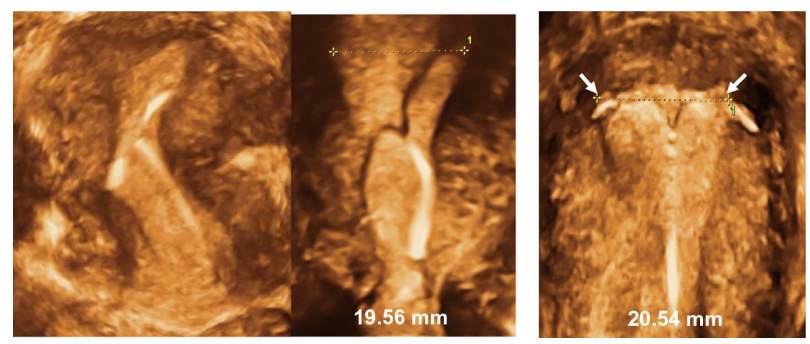

Figure 8 3-D ultrasonography: Abnormally located ParaGard intrauterine device (IUD) causing bleeding and pain (left) and middle (Mirena). Even if the IUD is apparently located in the correct position, the too-long transverse arm can cause painful contractions (right).

Note: The fundal transverse dimension in these cases (middle and right) is only approximately $2 \mathrm{~cm}$. Adapted from Ultrasound in Obstetrics and Gynaecology, Volume 34, Benacerraf BR, Shipp TD, Bromly B, Three-dimensional ultrasound detection of abnormally located intrauterine contraceptive devices which are the source of pelvic pain and abnormal bleeding, pages I I0-I I 5. Copyright (C 2009.49 


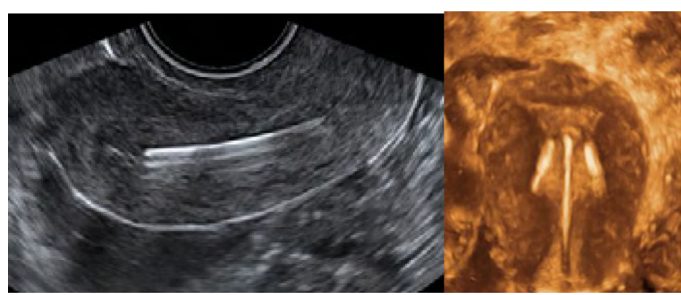

Figure 92 2-D/3-D ultrasonography: Position of the stem of the ParaGard intrauterine device (IUD), showing slight downward displacement (left). The arms of the IUD are unfolded and penetrate the muscular wall as the uterus is too small (right). Note: Although not measured, the fundal transverse diameter appears less than $2 \mathrm{~cm}$. Adapted from Ultrasound in Obstetrics and Gynaecology, Volume 34, Benacerraf BR, Shipp TD, Bromly B, Three-dimensional ultrasound detection of abnormally located intrauterine contraceptive devices which are the source of pelvic pain and abnormal bleeding, pages II $0-1$ I5. Copyright (C) 2009.49

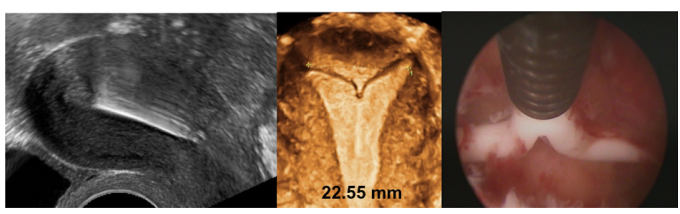

Figure 10 2-D/3-D ultrasonography: Another example of position of the stem of the Nova-T intrauterine device (IUD), showing slight downward displacement (left). The arms of the IUD are unfolded and penetrate the cornua of the uterus (middle, 3-D; right, hysteroscopy picture).

Note: The fundal transverse diameter is only $22.55 \mathrm{~mm}$.

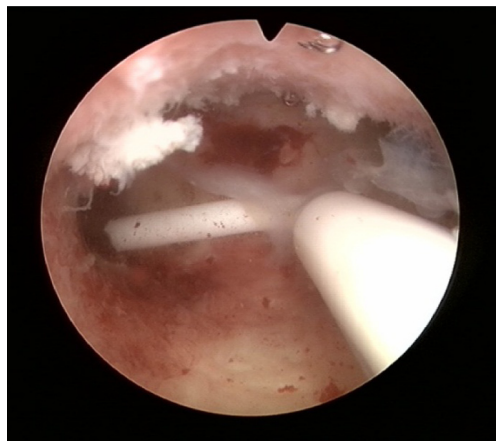

Figure II Mirena: shortened transverse arm after removal because of patient complaints and reinsertion under strict sterile conditions.
The most common reason for discontinuing the use of copper IUDs is increased menstrual blood loss (MBL). The magnitude of this increase is mainly related to the size of the device. With larger types of nonmedicated IUD, such as the Lippes Loop, monthly blood loss is about $70-80 \mathrm{~mL}$, which is approximately double that of normal menses. The amount of excess bleeding is less $(50-60 \mathrm{~mL})$ with smaller copper devices, such as the copper T series. ${ }^{53}$ Clinical trials suggest that MBL with the GyneFix 330 IUD is less than that associated with the TCu380A (ParaGard). ${ }^{54}$ With the small GyneFix 200 IUD, studies using a pictorial visual assessment technique suggest no significant increase in MBL after the first few months. ${ }^{22}$ This is attributed to the small size of the GyneFix 200 IUD. The copper surface area does not seem to have an effect on menstrual blood loss. ${ }^{55}$

Figure 12 illustrates the position of the frameless and flexible IUD in the uterine cavity, as well as the dimensional compatibility, even if the fundal transverse diameter is sometimes extremely small, as in young nulliparous and adolescent women.

Downward displacement and partial expulsion, a consequence of spatial discrepancy between the IUD and the uterine cavity leading to unintended pregnancies, can be avoided by anchoring the IUD (Table 3 ).

Removal for abnormal bleeding and pain complaints have been low in the studies reported in this paper, particularly with the smaller version ( $<1 / 100$ women per year at 3 years). Consequently, high continuation rates were recorded with the GyneFix 200 IUD at 3 years postinsertion (over 90\%), and continuation rates remained high during the subsequent years. ${ }^{21}$ This is in contrast with ParaGard and Mirena, which have low continuation rates in the order of $50 \%$, or less, at 5 years. ${ }^{56-58}$
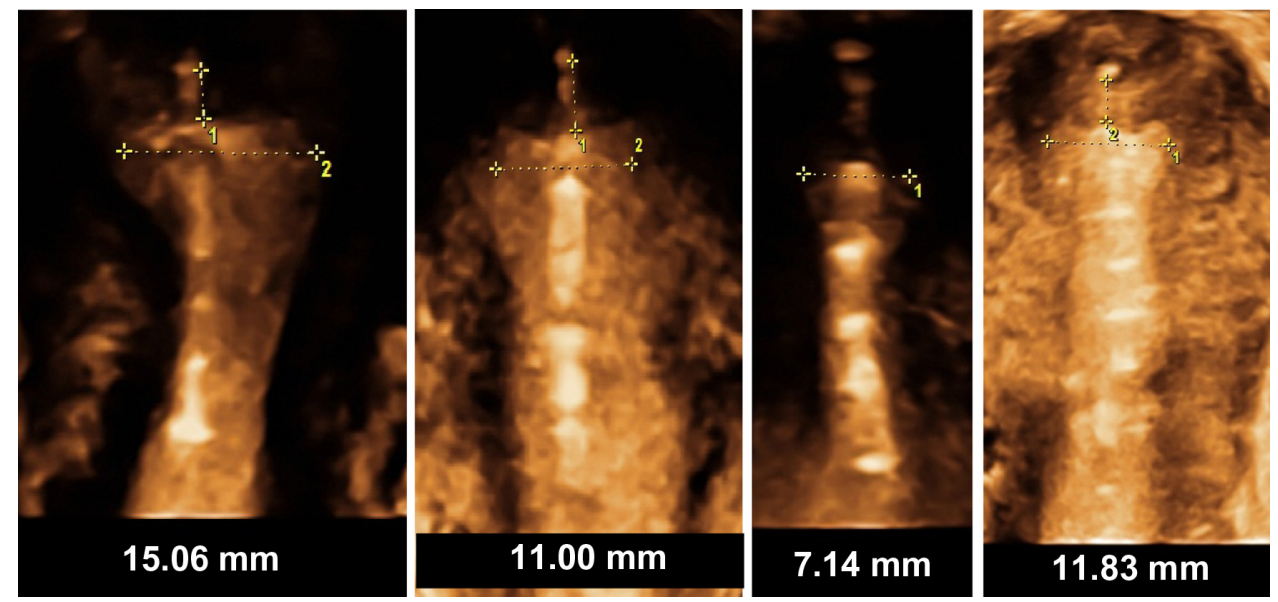

Figure 12 3-D ultrasound of GyneFix, illustrating the compatibility of the frameless intrauterine device with very narrow uterine cavities of young adolescent and nulliparous women. 
As the frameless technology is new, familiarity with the insertion procedure may be acquired only after a number of insertions have been completed, depending on the skill of the provider. Experience has shown that insertion failures and expulsions, in parous as well as nulliparous women, can be minimized to very low rates if providers follow a training course organized by the manufacturer. It is noteworthy that systematic training was not conducted in earlier studies, including in the GESEG study. Consequently, higher expulsion rates were noted when insertion training was inadequate or lacking in two of the studies. With GyneFix 200 , providers were properly trained and training has been further improved by the provision of the Home Uterine Trainer (see below).

Individual training is essential to learn the details to properly insert anchored IUDs, and will result in optimal performance and high continuation of use. Following training, providers can improve their skills and create confidence in the anchoring technique by using the home uterine model (Figure 13) before they start insertions in their patients. Unfortunately, this highly useful training material has only been available in recent years and this is one of the weaknesses that resulted in a number of failed insertions and early expulsions in two studies reported in this paper. ${ }^{19,25}$

Providing comfort at insertion is another important aspect of intrauterine contraception. Cervical preparation with misoprostol should probably be proposed, especially in some women with difficult intrauterine insertion, such as a nulliparous patient or a patient with a stenotic cervical os, as recommended by Vickery and Madden..$^{59}$ This is also the approach of the first author, although data from clinical studies show that routine use of misoprostol before IUD insertion is

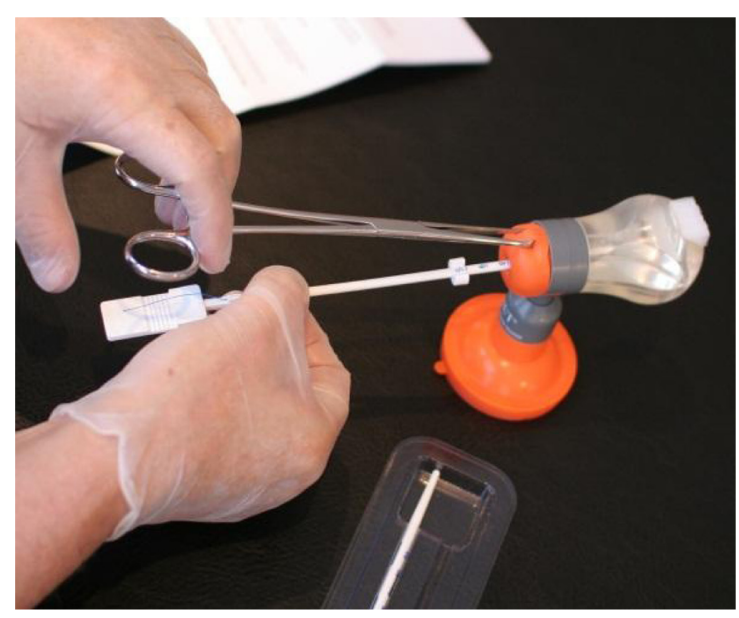

Figure 13 Home Uterine Trainer (HUT), suitable for home training of the frameless intrauterine device and intrauterine system insertion technique. not beneficial. An interesting review of methods of analgesia or cervical anesthesia for insertion of an IUD was prepared by the Faculty of Sexual and Reproductive Health Care Clinical Effectiveness Unit. ${ }^{60}$

One limitation is the relatively few studies conducted with the small GyneFix 200 IUD in nulliparous women. However, the anchoring technique is similar in all current anchored IUDs, as well as those in development, providing long-term experience. In general, younger and older women appreciate the comfort and peace of mind provided by the frameless IUD. Reports on severe adverse events (eg, perforation) are rare, which may be the result of compulsory training required by the manufacturer prior to performing actual insertion in patients. Additional studies are required in US women, particularly insertion-related studies, before the US Food and Drug Admininstration can provide market authorization.

\section{Conclusion}

Anchored, frameless IUDs have significant advantages over framed IUDs, as they fit in cavities of every size and shape. Moreover, one size fits virtually all cavities. They can therefore be named "precision intrauterine contraceptives." Many unintended pregnancies and induced abortions could be avoided in young women by providing suitable IUDs that result in a high continuation of use. In addition, if properly inserted, failed insertions and expulsion of the anchored IUD is rare.

Recommending the standard TCu380A (ParaGard) IUD or the Mirena LNG-IUS, primarily developed for use in parous women, for general use in nulliparous and adolescent women should be done with caution in the light of current scientific evidence, except if 3-D ultrasonography shows that the uterine cavity is sufficiently large.

\section{Acknowledgment}

We are grateful to Sarah Prager, MD, MAS, Associate Professor, Director of Family Planning, Department of Obstetrics and Gynecology, University of Washington for reviewing this paper.

\section{Disclosure}

Dirk Wildemeersch has been involved in the optimization of new, innovative, drug delivery systems for use in the uterus. He is currently advisor in devising new concepts in controlled release for contraception, gynecological treatment, and prevention of infectious diseases. The remaining authors report no conflicts of interest in this work. 


\section{References}

1. Blumenthal P, Voedisch A, Gemzell-Danielsson K. Strategies to prevent unintended pregnancy: increasing use of long-acting reversible contraception. Hum Reprod Update. 2011;17:121-137.

2. LiveStrong.com [webpage on the Internet]. Teen pregnancy rates in the USA. 2011. Available from: http://www.livestrong.com/article/12504teen-pregnancy-rates-usa. Accessed January 17, 2012.

3. Trussell J. Contraceptive failure in the United States. Contraception. 2011;83:397-404.

4. Goodman S, Hendlish SK, Reeves MF, Foster-Rosales A. Impact of immediate post-abortal insertion of intrauterine contraception on repeat abortion. Contraception. 2008:78;143-148.

5. Cleland K, Zhu H, Goldstuck N, Cheng L, Trussell J. The efficacy of intrauterine devices for emergency contraception: a systematic review of 35 years of experience. Hum Reprod. 2012;27:1994-2000.

6. Trussell J, Lalla AM, Doan QV, Reyes E, Pinto L, Gricar J. Cost effectiveness of contraceptives in the United States. Contraception. 2009;79:5-14.

7. Hasson HM. Clinical studies of the Wing Sound II metrology device. In: Zatuchni GI, Goldsmith A, Sciarra JJ, editors. Intrauterine Contraception: Advances and Future Prospects. Philadelphia: Harper and Row; 1984:126-141.

8. Kurz KH. Cavimeter uterine measurements and IUD clinical correlation. In: Zatuchni GI, Goldsmith A, Sciarra JJ, editors. Intrauterine Contraception: Advances and Future Prospects. Philadelphia: Harper and Row; 1984:142-162.

9. Kamal I, Hefnawi F, Ghonheim M, Talant M, Abdalla M. Dimensional and architectural disproportion between the intrauterine device and the uterine cavity: a cause of bleeding. Fert Steril. 1971;22:514-521.

10. Roy S, Cooper D, Mishell DR. Experience with three different models of the Copper T intrauterine contraceptive device in nulliparous women. Am J Obstet Gynecol. 1974;119(3):414-417.

11. Gadelha Da Costa A, Filho FM, Ferreira AC, Spara P, Mauad FM. Uterine volume in adolescents. Ultrasound Med Biol. 2004;30: 7-10.

12. Bulletti C, de Ziegler D, Polli V, Diotalle L, Del Ferro E, Flamigni C. Uterine contractility during the menstrual cycle. Hum Reprod. 2000; 15 Suppl 1:81-89.

13. Petersen KR, Brooks L, Jacobsen B, Skouby SO. Intrauterine devices in nulliparous women. Adv Contracept. 1991;7:333-338.

14. Canteiro R, Bahamondes V, dos Santos Fernandes A, Espejo-Arce X, Marchi NM, Bahamondes L. Length of the endometrial cavity as measured by uterine sounding and ultrasonography in women of different parities. Contraception. 2010;81:515-519.

15. Zohav E, Anteby EY, Orvieto R. Use of three-dimensional ultrasound in evaluating the intrauterine position of a levonorgestrel-releasing intrauterine system. Reprod Biomed Online. 2007;14:495-497.

16. Benacerraf BR, Shipp TD, Lyons JG, Bromley B. Width of the normal uterine cavity in premenopausal women and effect of parity. Obstet Gynecol. 2010;116(2 Pt 1):305-310.

17. Wildemeersch D, Van der Pas H, Thiery M, Van Kets H, Parewijck W, Delbarge W. The Copper-Fix (Cu-Fix): a new concept in IUD technology. Adv Contracept. 1988;4:197-205.

18. Van Kets H, Vrijens M, Van Trappen Y, et al. The frameless GyneFix intrauterine implant: a major improvement in efficacy, expulsion and tolerance. Adv Contracept. 1995;11:131-142.

19. Wu S, Hu J, Wildemeersch D. Performance of the frameless GyneFix and the TCu380A IUDs in a three-year multicenter randomized comparative trial in parous women. Contraception. 2000;61:91-98.

20. Wildemeersch D, Andrade A. Commentary - A historical note on the development of the frameless IUD. Contraception. 2010;81: 172-176.

21. Cao X, Zhang W, Zhao X, et al. Three-year efficacy and acceptability of the GyneFix 200 intrauterine device. Contraception. 2004;69:207-211. Erratum. Contraception. 2006;73:315-317.

22. Wildemeersch D, Rowe PJ. Assessment of menstrual blood loss in Belgian users of the frameless copper-releasing IUD with copper surface are of $200 \mathrm{~mm}^{2}$ and users of a copper-levonorgestrel-releasing intrauterine system. Contraception. 2004;70:169-172.
23. Batár I, Wildemeersch D, Vrijens M, Delbarge W, Temmerman M, Gbolade BA. Preventing abortion and repeat abortion with the GyneFix intrauterine implant system - preliminary results. Adv Contracept. 1998;14(2):91-96.

24. Gbolade BA. Immediate insertion of the postabortion version of the GyneFix intrauterine implant system. Contemp Rev Obstet Gynaecol. 1999;11:29-33.

25. Martinez F, Gimenez E, Hernandez G, et al. Experience with GyneFix insertions in Spain: favorable acceptance of the intrauterine contraceptive implant with some limitations. Contraception. 2002;66: 315-320.

26. Wildemeersch $\mathrm{D}$. The force required to remove the frameless 0 -suture anchoring system: comparison between pre- and postmenopausal women. Contraception. 2004;69:513-515.

27. Trussell J. Contraceptive failure in the United States. Contraception. 2011;83:397-404.

28. Winner B, Peipert JF, Zhao Q, et al. Effectiveness of long-acting reversible contraception. N Engl J Med. 2012;366:1998-2007.

29. Stuart JE, Secura GM, Zhao Q, Pittman ME, Peipert JF. Factors associated with 12-month pill, patch, and ring users. Obstet Gynecol. 2013;121:330-336.

30. Finer LB, Jerman J, Kavanaugh ML. Changes in use of long-acting contraceptive methods in the United States, 2007-2009. Fertil Steril. 2012;98:893-897.

31. Haimovich S. Profile of long-acting reversible contraception users in Europe. Eur J Contracept Reprod Health Care. 2009;14: 187-195.

32. Secura GM, Allsworth JE, Madden T, Mullersman JL, Peipert JF. The Contraceptive CHOICE Project: reducing barriers to long-acting reversible contraception. Am J Obstet Gynecol. 2010;203:115.e1-e7.

33. Mestad R, Secura G, Allsworth JE, Madden T, Zhao Q, Peipert JF. Acceptance of long-acting reversible contraceptive methods by adolescent participants in the Contraceptive CHOICE Project. Contraception. 2011;84:493-498.

34. Wellings K, Zhihong Z, Krentel A, Barrett G, Glasier A. Attitudes towards long-acting reversible methods of contraception in general practice in the UK. Contraception. 2007;76:208-214.

35. Kaunitz A. Changing the contraceptive paradigm: making long-acting methods the default option. Medscape Today. 2012. Available from: http:// www.medscape.com/viewarticle/765969. Accessed March 4, 2013.

36. Trussell J, Henry N, Hassan F, Prezioso A, Law A, Filonenko A. Burden of unintended pregnancy in the United States: potential savings with increased use of long-acting reversible contraception. Contraception. 2013;87:154-161.

37. American Congress of Obstetricians and Gynecologists. Committee opinion number 539: Adolescents and long-acting reversible contraception: implants and intrauterine devices. 2012. Available from: http:// www.acog.org/Resources\%20And\%20Publications/Committee $\%$ 20Opinions/Committee $\% 20$ on $\% 20$ Adolescent $\% 20$ Health $\% 20$ Care/Adolescents\%20and\%20Long-Acting\%20Reversible $\% 20$ Contraception.aspx. Accessed March 4, 2013.

38. Blumenthal PD, Gemzell-Danielsson K, Marintcheva-Petrova M. Tolerability and clinical safety of Implanon. Eur J Contracept Reprod Health Care. 2008;13 Suppl 1:29-36.

39. Lyus R, Lohr P, Prager S. Use of Mirena LNG-IUS and Paragard CuT380A intrauterine devices for nulliparous women. Contraception. 2010;81:367-371.

40. Bahamondes MV, Hidalgo MM, Bahamondes L, Monteiro I. Ease of insertion and clinical performance of the levonorgestrelreleasing intrauterine system in nulligravidas. Contraception. 2011; 84:e11-e6.

41. Marions L, Lövkvist L, Taube A, Johansson M, Dalvik H, Øverlie I. Use of the levonorgestrel releasing-intrauterine system in nulliparous women - a non-interventional study in Sweden. Eur J Contracept Reprod Health Care. 2011;16:126-134.

42. Hubacher D. Copper intrauterine device used by nulliparous women:review of side effects. Contraception. 2007;75:S8-S11. 
43. Paterson H, Ashtin J, Harisson-Woolrych. A nationwide cohort study of the use of the levonorgestrel intrauterine device in New Zealand adolescents. Contraception. 2009;79:433-438.

44. Suhonen S, Haukkamaa M, Jakobsson T, Rauramo I. Clinical performance of a levonorgestrel-releasing intrauterine system and oral contraceptives in young nulliparous women: a comparative study. Contraception. 2004;69:407-412.

45. Andersson K, Odlind V, Rybo G. Levonorgestrel releasing and copper releasing (Nova T) IUCDs during five years of use. A randomized comparative study. Contraception. 1994;49:56-72.

46. Luukkainen T, Allonen H, Haukkamaa M, et al. Effective contraception with the levonorgestrel-releasing intrauterine device: 12-month report of a European multicenter study. Contraception. 1987;36:160-179.

47. Rivera R, Chen-Mok M, McMullen S. Analysis of client characteristics that may affect early discontinuation of the TCu-380A IUD. Contraception. 1999;60:155-160.

48. Teal SB, Sheeder J. IUD use in adolescent mothers: retention, failure and reasons for discontinuation. Contraception. 2012;85:270-274.

49. Benacerraf BR, Shipp TD, Bromly B. Three-dimensional ultrasound detection of abnormally located intrauterine contraceptive devices which are the source of pelvic pain and abnormal bleeding. Ultrasound Obstet Gynecol. 2009;34:110-115.

50. Braaten KP, Benson CB, Maurer R, Goldberg AB. Malpositioned intrauterine contraceptive devices: risk factors, outcomes, and future pregnancies. Obstet Gynecol. 2011;118:1014-1020.

51. Andrade CMA, Barbieri M, Nowak PM, Torloni MR, Araujo FF, Guazzelli CAF. Is three-dimensional ultrasound better for the identification of the levonorgestrel intrauterine system? 12th Congress of the European Society of Contraception and Reproductive Health Care; Athens, Greece; June 22-23, 2012.
52. Wildemeersch D. The effective copper surface area differs substantially between that of the frameless copper IUD and that of conventional copper IUDs: a comment. J Fam Plann Reprod Health Care. 2006; 32:54.

53. Andrade TL, Andrade MD, Pizzaro Orchard E. Quantitative studies on menstrual blood loss in IUD users. Contraception. 1987;36:129-144.

54. [No authors listed]. The TCu380A IUD and the frameless "FlexiGard", interim three-year data from an international multicenter trial. UNDP, UNFPA, and WHO Special Programme of Research, Development and Research Training in Human Reproduction, World Bank: IUD Research Group. Contraception. 1995;52:77-83.

55. Milsom I, Rybo G, Lindstedt G. The influence of copper surface area on menstrual blood loss and iron status in women fitted with an IUD. Contraception. 1990;41:271-281.

56. Sivin I, Shaaban M, Odlind V, et al. A randomized trial of the Gyne T 380 and Gyne T 380 Slimline intrauterine copper devices. Contraception. 1990;42:379-389.

57. Andersson K, Odlind V, Rybo G. Levonorgestrel releasing and copper releasing (Nova T) IUCDs during five years of use. A randomized comparative study. Contraception. 1994;49:56-72.

58. Sivin I, el Mahgoub S, McCarthy T, et al. Long-term contraception with the levonorgestrel $20 \mathrm{mcg} /$ day $(\mathrm{LNg} 20)$ and the copper T $380 \mathrm{Ag}$ intrauterine devices: a five-year randomized study. Contraception. 1990;42:361-378

59. Vickery Z, Madden T. Difficult intrauterine contraception insertion in a nulligravid patient. Obstet Gynecol. 2011;117:391-395.

60. Faculty of Sexual and Reproductive Healthcare, data on file, FSRH Clinical Effectiveness Unit (2009).
International Journal of Women's Health

\section{Publish your work in this journal}

The International Journal of Women's Health is an international, peerreviewed open-access journal publishing original research, reports, editorials, reviews and commentaries on all aspects of women's healthcare including gynecology, obstetrics, and breast cancer. The manuscript management system is completely online and includes

\section{Dovepress}

a very quick and fair peer-review system, which is all easy to use. Visit http://www.dovepress.com/testimonials.php to read real quotes from published authors. 